\title{
Stability of Coal Pillar and Roof Movement Characteristics in Roadway Backfill Mining
}

\author{
Hai Lin $\mathbb{D},{ }^{1,2}$ Renshu Yang, ${ }^{1,2}$ Yongliang Li $\mathbb{D},{ }^{3}$ and Shizheng Fang $\mathbb{D}{ }^{1,2}$ \\ ${ }^{1}$ School of Civil and Resource Engineering, University of Science and Technology Beijing, Beijing 100083, China \\ ${ }^{2}$ Beijing Key Laboratory of Urban Underground Space Engineering, University of Science and Technology Beijing, \\ Beijing 100083, China \\ ${ }^{3}$ School of Energy and Mining Engineering, China University of Mining and Technology (Beijing), Beijing 100083, China \\ Correspondence should be addressed to Hai Lin; b20200019@xs.ustb.edu.cn
}

Received 16 January 2021; Revised 17 February 2021; Accepted 2 March 2021; Published 23 March 2021

Academic Editor: Qianqian Wang

Copyright (c) 2021 Hai Lin et al. This is an open access article distributed under the Creative Commons Attribution License, which permits unrestricted use, distribution, and reproduction in any medium, provided the original work is properly cited.

\begin{abstract}
In order to explore the stability of coal pillar and the characteristics of roof movement during the process of roadway backfill mining (RBM), the 301 backfilling test working face of Ordos Chahasu coal mine is taken as the background. Based on the expansive pressure arch theory, the evolution process of the stope expansive pressure arch in RBM is studied; by establishing a mechanical model for the stability of coal pillars, the interactions between the height, width, and the maximum number of branches are obtained. When the width and height of the branch are both $5 \mathrm{~m}$, the optimal number of the branches is obtained. Then, by establishing a mechanical model for the subsidence of the immediate roof, the process of the immediate roof subsidence is divided into three stages, namely, the formation stage of the local pressure arch, the merge stage of the pressure arch, and the expansion stage of the pressure arch. In addition, using the numerical method, the alternate bearing process of coal pillars and filling bodies and the change of the maximum supporting stress are studied, and the evolution of the pressure arch bearing structure above the stope and the staged subsidence characteristics of the roof are analyzed. The on-site test showed that the coal pillar has a good stability during the mining process. The maximum stress of the coal pillar is $16.5 \mathrm{MPa}$, and the maximum stress of the filling body is $9 \mathrm{MPa}$. The maximum settlement of the immediate roof is $102 \mathrm{~mm}$, indicating that the roof control effect is good. This research will play an important role on engineering practice.
\end{abstract}

\section{Introduction}

The major coal mining region of China has gradually shifted to the western region, and the high-intensity coal mining in the western region has brought a series of social and environmental problems. The traditional caving mining method causes the overlying strata to collapse and develop to the surface, causing surface buildings to settle, soil erosion [1-3], and a large amount of industrial waste, such as gangue, is produced, and the ecological environment continues to deteriorate. In order to reduce the disturbance to the overlying strata and control both the subsidence and deformation of the ground surface, the method of subsidence reduction mining should be adopted $[4,5]$. At present, there are mainly two mining systems, partial mining and filling mining, to control surface subsidence [6]. However, partial mining requires a large number of coal pillars and has a low recovery ratio and a serious waste of resources. The long-term load-bearing strength of coal pillars is gradually weakened, finally causing serious instability and damage [7, 8]. Backfill mining includes longwall backfill mining and roadway backfill mining (RBM). The longwall backfill mining space is small, the mining and backfilling are mutually restricted, and the roof control effect is poor; after the RBM adopts continuous mining and continuous backfilling technology, the mining and backfilling are not carried out in the same branch and do not affect each other. The roof control effect is more prominent [9].

RBM is a support system dominated by backfilling bodies to control the subsidence of the overlying strata 
$[10,11]$. In the staged mining process, the coal pillar and the filling body bear the load of the overlying strata. The stability of the coal pillar is the key factor that determines the roof movement and the overlying strata structure. Most of the studies focused on the strength of a single coal pillar [12-16], and the stability of the coal pillar group of RBM are ignored. In terms of roof movement and control mechanism, Zhang et al. [17] explored the development mechanism of waterconducting fracture in the overlying rock in RBM; Sun et al. [18] established a mechanical model of the roadway backfilling stope, deduced the stope roof equation and the coal pillar load-bearing formula, and put forward the basis for coal pillar instability; Deng et al. [19] established a mechanical model for the roof movement of extrathick coal seams and proposed the roof instability and fracture conditions; the above studies explored the roof and overlying strata movement mechanism of RBM and promoted the field application of RBM. However, these studies did not consider the influence of RBM coal pillar group stability on roof movement; in fact, as the length of the working face increases, the load on the coal pillars also increases, which intensifies the subsidence of the stope roof. Therefore, it is necessary to consider the influence of the stability of the coal pillars on the roof subsidence to ensure that the roof deformation of the stope is controlled within a reasonable range.

Based on the theory of expansive pressure arch and ultimate strength theory, this paper established a mechanical model of the coal pillar group for RBM, derived the immediate roof subsidence calculation formula of the stope, and proposed the settlement calculation method of the overlying strata, which provides reference for the parameter design of the branch. Through numerical simulation, the load-bearing process of coal pillars and filling body and the characteristics of roof movement in the process of RBM are studied; finally, the on-site test using RBM has been adopted in Chahasu Mine and has achieved good results, hoping to provide a theoretical basis for field applications under the same conditions.

\section{Project Overview}

2.1. Engineering Background. Chahasu Mine is located in Ordos City, Inner Mongolia, China (Figure 1(a)). The climate in this area is arid, and the surface vegetation is sparse (Figure 1(b)). The annual output of gangue reaches 1 million tons, which is accumulated on the surface, and the ecological environment continues to deteriorate. Therefore, Chahasu Mine has established a RBM test face in the 31st mining area. The backfilling materials are mainly gangue, fly ash, cement, and mine water.

This mining is mainly $3-1$ coal; the average thickness of the coal seam is $5 \mathrm{~m}$, the coal seam is nearly horizontal with the inclination angle of $1^{\circ} \sim 3^{\circ}$, and the average buried depth is $400 \mathrm{~m}$. Assuming that the thickness of each rock strata in the mining area remains unchanged, the typical drilling histogram is shown in Figure 1(c). The immediate roof is mudstone with $2 \mathrm{~m}$ in thickness, the main roof is sandy mudstone with $10 \mathrm{~m}$ in thickness, and the immediate bottom is mudstone $12 \mathrm{~m}$ in thickness.

2.2. RBM Technology. As shown in Figure 2, the mining and backfilling at the working face are divided into two stages with four phases. First, $5 \mathrm{~m}$ wide coal pillars are mined every $15 \mathrm{~m}$ and filled, and then, a $5 \mathrm{~m}$ coal pillar in the middle of the $15 \mathrm{~m}$ coal pillar is mined and filled, this is the first and second phases. In the third and fourth phases, the $15 \mathrm{~m}$ coal pillars are mined and backfilled with $5 \mathrm{~m}$ coal pillars on the left and right sides, and all the coal pillars of the branches are finally mined. During the mining process, coal pillars are used on both sides of the branches during the first and second phases, which is the first stage of mining. During the third and fourth phases of mining, at least one side is the filling body, which is the second stage of mining. In fact, due to geological conditions and technical reasons, the filling ratio will not reach $100 \%$, and it will take some time for the filling body to reach the design strength. Therefore, before the filling body and the immediate roof are contacted, the load of the overlying strata is mainly borne by the coal pillars, and the stability of the coal pillar determines the control effect of the stope roof.

\section{Stability Analysis of Coal Pillars}

3.1. The Evolution Process of the Expansive Pressure Arch in Roadway Backfill Mining. As shown in Figure 3, after the branch is excavated, the roof load is transferred to the coal pillars on both sides through the pressure arch, and significant local pressure arches between adjacent coal pillars are generated. With the continuous advancement of the working face, the pressure arches continued to spread outward, superimposed on the coal pillars, and the adjacent pressure arches began to merge, and eventually, an expansive pressure arch composed of high-stress bundles was formed above the stope.

There is a local pressure arch between adjacent coal pillars, and the upper part of the entire stope is an expansive pressure arch. The rock mass outside the arch is compressed, and the rock mass inside the arch is stretched. As the working face excavates, the local stress arch gradually merges, rises, and expands. An enlarged pressure arch is formed. The stability of the overlying strata of the entire stope is determined by the local pressure arch and the expansive pressure arch.

3.2. Coal Pillar Load and Strength. As shown in Figure 4, according to the expansive pressure arch theory [20], after the first stage of mining, the coal pillar in the center of the working face bears the greatest load. Without considering the support conditions, if the bearing capacity of the coal pillar in the center meets the requirements, then all coal pillars in the working face will meet the requirements. 

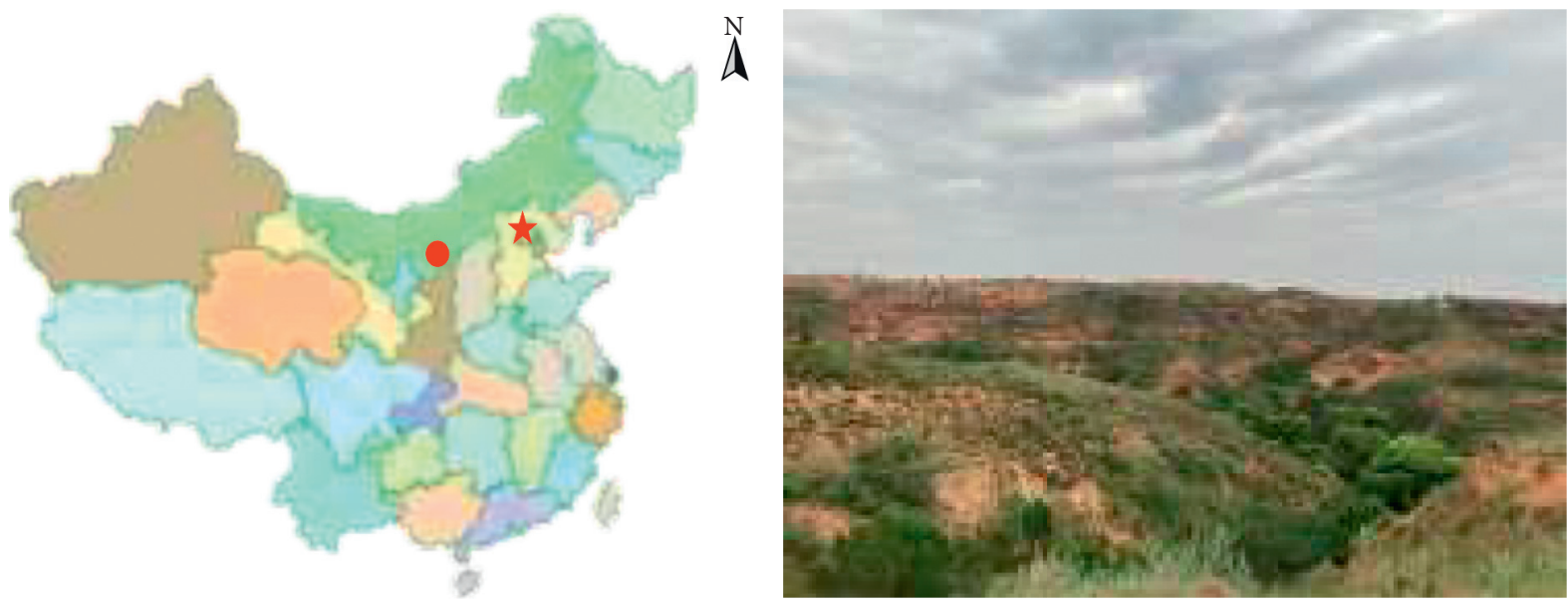

Beijing

Chahasu Coal Mine

(a)

(b)

\begin{tabular}{|c|c|c|}
\hline Lithology & Strata & Thickness (m) \\
\hline & Sand & 9 \\
\hline & Boulderstone & 97 \\
\hline & Gritstone & 57 \\
\hline & Sand mudstone & 7 \\
\hline & Gritstone & 14 \\
\hline & Sandy mudstone & 16 \\
\hline & Siltstone & 12 \\
\hline & Sandy mudstone & 15 \\
\hline & Soulderstone & 25 \\
\hline & Sandy mudstone & 59 \\
\hline & Fine Sandstone & 23 \\
\hline & Medium Sandstone & 44 \\
\hline & Sandy mudstone & 2 \\
\hline & Medium Sandstone & 18 \\
\hline & Sandy mudstone & 10 \\
\hline & Fine Sandstone & 2 \\
\hline
\end{tabular}

(c)

Figure 1: Chahasu Mine location and drill hole histogram.

3.2.1. Coal Pillar Load. The maximum load of the coal pillar in the working face is as follows[20]:

$$
\begin{aligned}
p_{\text {max }} & =2 b \gamma H, \\
H & =\frac{W k_{s}}{2 f_{k}}, \\
W & =B+2 h \tan \left(45^{\circ}-\frac{\varphi}{2}\right), \\
B & =n b,
\end{aligned}
$$

where $H$ is the height of the expansive pressure arch, $\mathrm{m}, W$ is the width of the expansive pressure arch, $\mathrm{m}, B$ is the width of the working face, $\mathrm{m}, n$ is the number of branches, $p_{\max }$ is the maximum load of the coal pillar, $\mathrm{MPa}, b$ is the width of the branch, $\mathrm{m}, \gamma$ is the bulk density of the rock formation, $\mathrm{kN} \cdot \mathrm{m}^{-3}, f_{k}$ is the general coefficient of the overlying strata, which is generally equal to the $1 / 10$ of the uniaxial compressive strength of the rock, $h$ is the mining height, $\mathrm{m}, \varphi$ is the internal friction angle, , and $k_{\mathrm{s}}$ is the pressure arch correction coefficient [20] and can be expressed as

$$
k_{\mathrm{s}}= \begin{cases}4.0 \sim 5.0, & f_{k} \leq 0.8, \text { unstable rock; } \\ 3.0 \sim 4.0, & 0.8<f_{k} \leq 4, \text { medium rock; } \\ 1.5 \sim 2.0, & 5<f_{k} \leq 8, \text { hard rock. }\end{cases}
$$

Then, substituting formulas (3) and (4) into formula (2), the relationship between the height of the expansive pressure arch, the width of the coal pillar, and the number of branches can be written as 


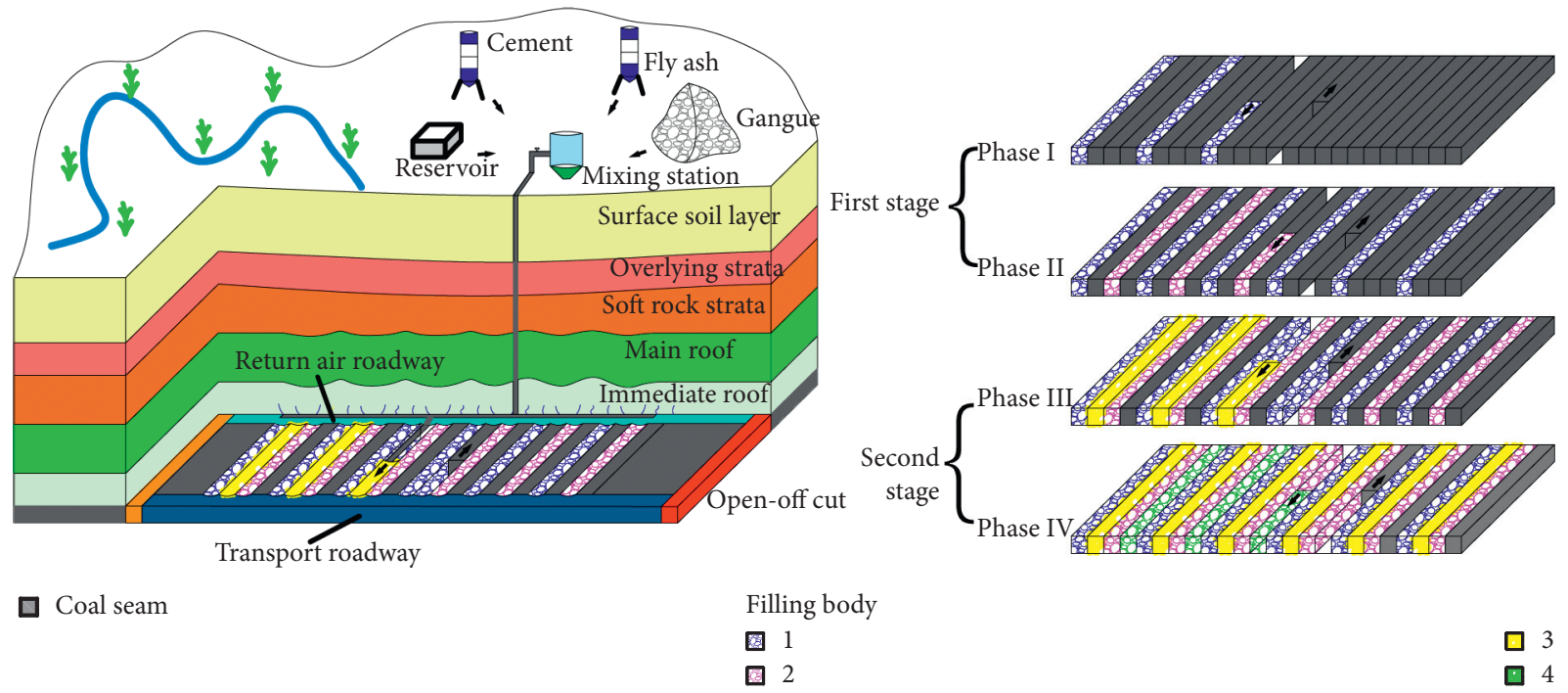

FIgURE 2: Working face layout and mining method.

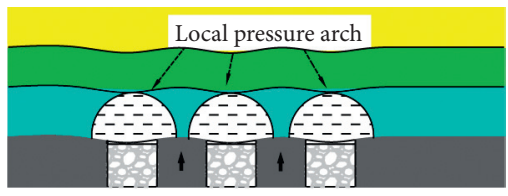

(a)

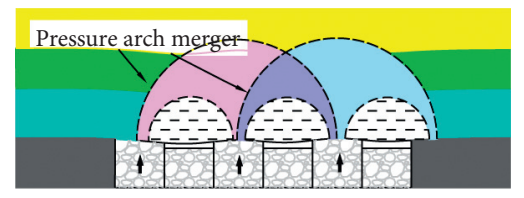

(b)

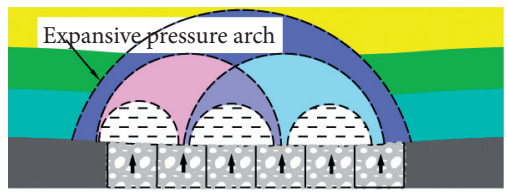

(c)

FIgURE 3: The evolution process of the expanding pressure arch in RBM. (a) Local pressure arch. (b) Merging pressure arch. (c) Expansive pressure arch.

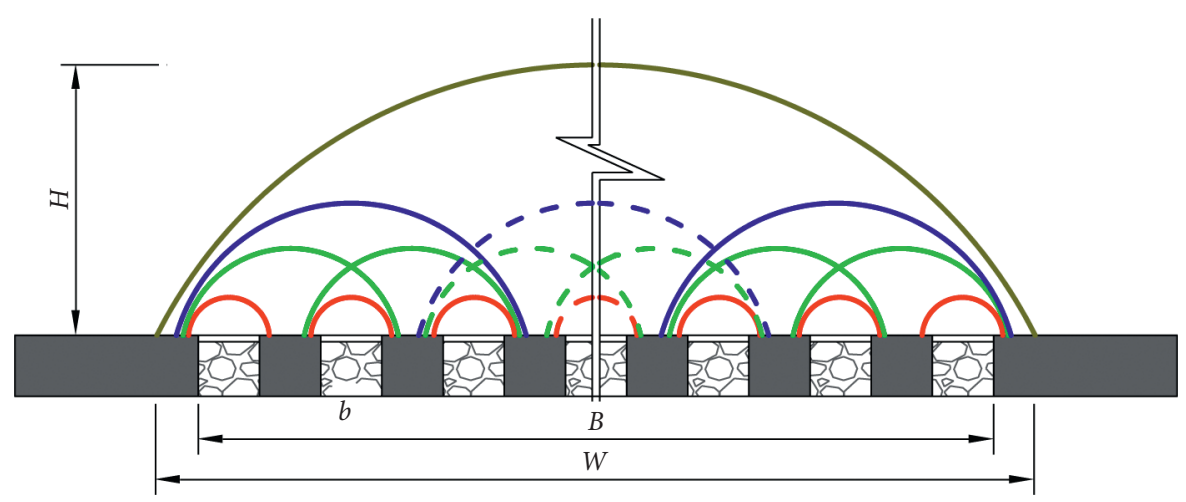

FIGURE 4: Schematic diagram of expansive pressure arch theory.

$$
H=\left[n b+2 h \tan \left(45^{\circ}-\frac{\varphi}{2}\right)\right] \frac{k_{s}}{2 f_{k}} .
$$

3.2.2. Coal Pillar Strength. There are many factors that influence the strength of coal pillars, which are not only dependent on the strength of the coal itself but are also related to the size, internal structure, and support strength of the coal pillar. For a long time, many scholars and experts have put forward two coal pillar strength formulas with linear and exponential types based on the field experience and summary $[21,22]$. In this paper, without considering the supporting conditions, the exponential formula is used to calculate the strength of coal pillars:

$$
\sigma_{p}=\sigma_{m} \frac{b^{A}}{h^{B}},
$$

where, according to the empirical formula parameters of coal pillar strength proposed by the South African scholar Salamon [20], $\sigma_{m}=7.2 \mathrm{MPa}, A=0.46$, and $B=0.66$.

3.3. Stability Analysis of the Coal Pillar. According to the ultimate strength theory, when the load of the coal pillar reaches the ultimate strength, the bearing capacity of the coal 
pillar decreases to zero and begins to lose stability. In RBM, the retention time of the coal pillars will not be too long. When the central coal pillar is in a state of limit equilibrium, formulas (1) and (7) should be combined to determine the maximum number of branches $n$ in the working face to ensure the stability of the coal pillar.

By consulting the geological data of No. 31 mining area of Chahasu Mine, the weighted average of the physical and mechanical parameters of the overlying strata are as follows: the bulk density $\gamma$ is $25 \mathrm{kN} \cdot \mathrm{m}^{-3}$, the internal friction angle is $35^{\circ}$, the cohesion $c$ is $2 \mathrm{MPa}$, the general coefficient $f_{k}$ is 4.6 , the lateral pressure coefficient is 1.2, and the pressure arch correction coefficient $k_{s}$ is 3.625 . Assuming the mining height is $3.5 \mathrm{~m}, 4 \mathrm{~m}, 4.5 \mathrm{~m}$, and $5 \mathrm{~m}$ and the width of the branch is $3.5 \mathrm{~m}, 4 \mathrm{~m}, 4.5 \mathrm{~m}$, and $5 \mathrm{~m}$, the strength of the coal pillar and the load curve are obtained, as shown in Figure 5. The integer value at the intersection of the coal pillar load and strength in the curve can determine the maximum number of branches in a mining cycle.

It can be seen from Figure 5 that when the branch width $b$ and the mining height $h$ remain unchanged, the coal pillar load increased approximately linearly with the increase in the number of branches $n$, and the coal pillar strength remained unchanged; when the number of branches $n$ exceeds the critical value, the coal pillar load increases approximately linearly. The coal pillar load is greater than the strength of the coal pillar, and the coal pillar may begin to lose. The larger the width $b$ of the branch is, the smaller the number $n$ of the branch where the coal pillar reaches the critical strength. In addition, the mining height $h$ has a significant impact on the coal pillar strength. As the mining height $h$ increases, the coal pillar strength begins to decrease, and the critical number of branches $n$ gradually decreases.

In summary, increasing the width of the branch is beneficial to increase the strength of a single coal pillar, reduce the distance of mechanical movement, and improve the mining efficiency. However, the excessive width of the branch limits the number of branches in the working face $n$, and the coal pillar parameter needs to be optimized according to the on-site conditions; taking the roof conditions and the flexibility of the machinery of the roadheader into account, the mining height is set to $5 \mathrm{~m}$, and the maximum excavation width of the roadheader is $5.5 \mathrm{~m}$. Therefore, the width of the branch is designed to be $5 \mathrm{~m}$, and the maximum number of branches in a mining cycle is 52 .

\section{Calculation of Roof Subsidence in RBM}

4.1. Mechanics Model of Immediate Roof Subsidence. The RBM technology is completed by filling in different stages. In order to study the influence of the stope roof pressure arch on the movement characteristics of roof subsidence during the staged mining process, the immediate roof is regarded as the beam structure, the coal pillars and the filling body are regarded as elastic foundations, and then, the elastic foundation beam analysis model is established, as shown in Figure 6 , where $h$ is the height of the coal seam, $b$ is the width of the branch, $k_{1}$ is the elastic coefficient of the coal pillar, and $k_{2}$ is the elastic coefficient of the filling body.
According to the description in Section 2, the immediate roof subsidence is mainly divided into three parts. The first part is the subsidence caused by the coal pillar as the main bearing body in the first stage of mining; the second part is the subsidence caused by the first-stage filling body as the main bearing body in the second-stage of mining; when the second-stage filling body reaches a certain strength, all the filling bodies bear the load, and the roof subsidence produced during this period is the third part; the immediate roof settlement $d$ can be expressed as

$$
d=d_{1}+d_{2}+d_{3},
$$

where $d_{1}$ and $d_{2}$ are the settlement of the immediate roof during the first and second stages, respectively, and $d_{3}$ is the settlement of the roof after all the weight of the overlying strata is transferred to the filling body.

\subsection{Immediate Roof Settlement Calculation}

4.2.1. Immediate Roof Settlement $d_{1}$. As shown in Figure 7, after the first stage of mining is completed, the overlying strata load is borne by the coal pillar. According to the concept of the yield zone of the coal pillar proposed by $\mathrm{AH}$ Wilson [23-26], there is a high-stress core area in the center of the bearing coal pillar due to the constraints, and the supporting capacity of the plastic failure zone on both sides is close to zero, and the width of the plastic failure zone can be expressed as

$$
r_{p}=\frac{h \lambda}{2 \tan \varphi} \ln \left(1+\frac{\sigma \tan \varphi}{c}\right),
$$

where $r_{p}$ is the width of the plastic failure zone, $\mathrm{m}, \sigma$ is the ultimate strength of the coal pillar, MPa, $\lambda$ is the lateral pressure coefficient of the interface between the plastic failure area and the high-stress core area of the coal pillar, and its value is equal to Poisson's ratio of the coal pillar, and $c$ is the cohesion of the coal pillar, MPa.

Assuming that the width of the high-stress core area is $C_{l}$, it can be seen that

$$
C_{l}=b-2 r_{p} .
$$

The average stress acting on the coal pillar $\sigma_{z}$ can be written as

$$
\sigma_{z}=\frac{C_{l}}{b} p_{\max } .
$$

After the first stage of mining, the maximum settlement of the immediate roof is

$$
d_{1}=h \frac{\sigma_{z}}{E_{c}}=\frac{h C_{l} p_{\max }}{b E_{c}}
$$

where $E_{c}$ is the Young's modulus of coal, GPa.

4.2.2. Immediate Roof Settlement $d_{2}$. After the first stage of mining, the amount of roof settlement is $d_{1}$, and the filling height is $h-d_{1}$. In the second-stage mining, the overlying strata load is mainly supported by the first-stage filling body. 

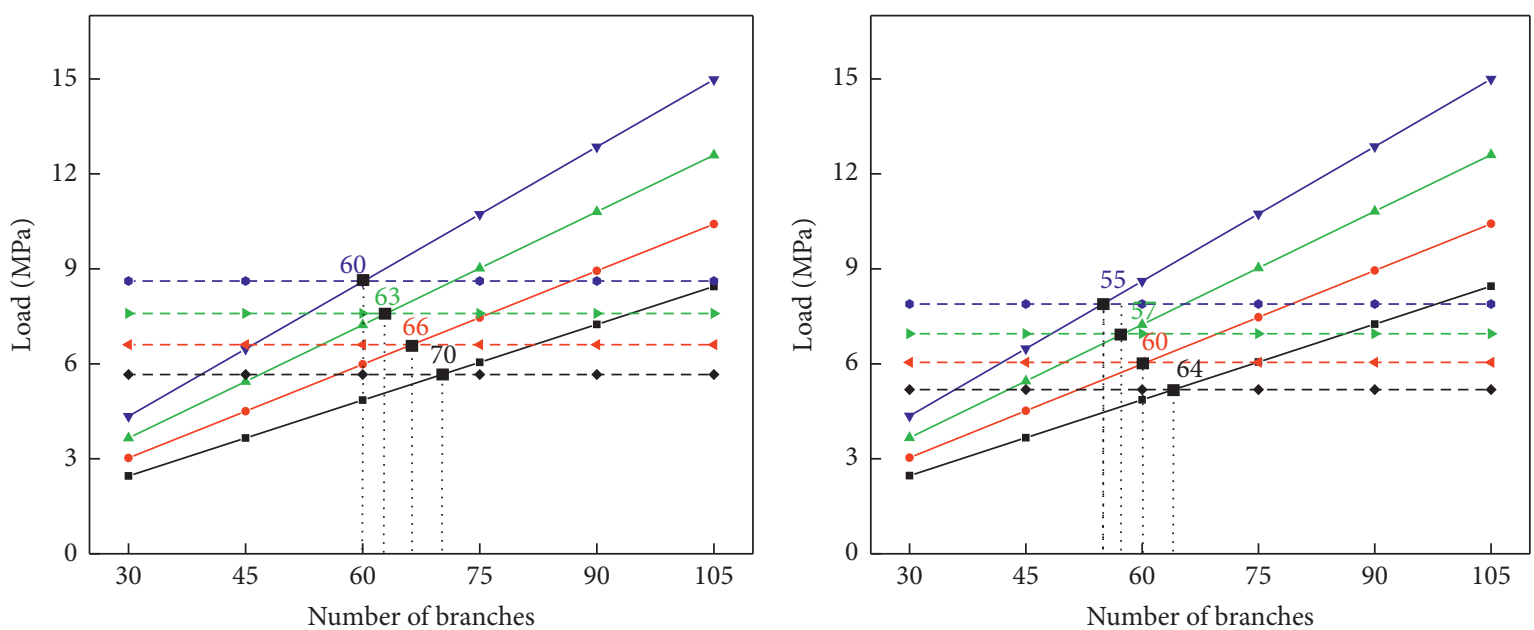

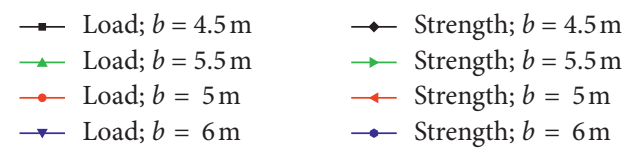

(a)

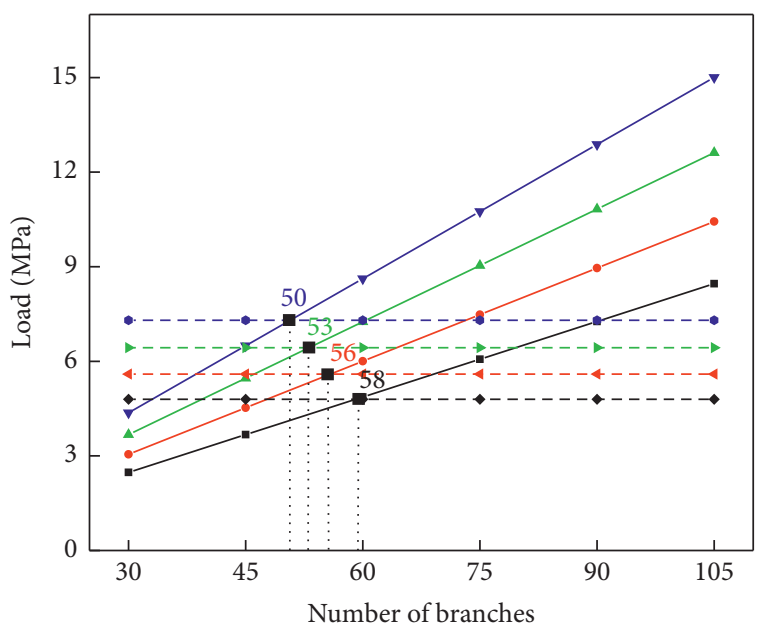

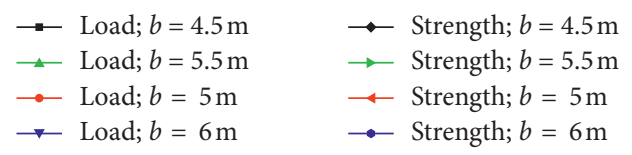

(c)

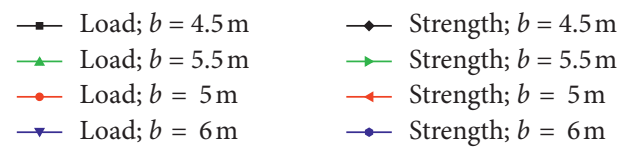

(b)

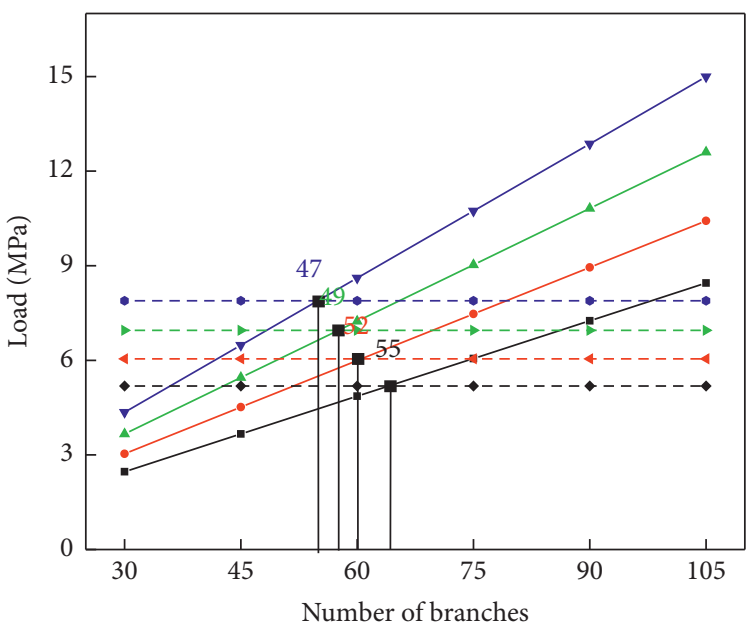

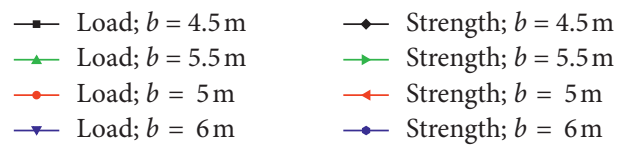

(d)

Figure 5: Coal pillar strength and coal pillar load. (a) $h=3.5 \mathrm{~m}$. (b) $h=4 \mathrm{~m}$. (c) $h=4.5 \mathrm{~m}$. (d) $h=5 \mathrm{~m}$.

According to equations (1), (9), and (10), the maximum settlement of the immediate roof after the second-stage mining can be calculated as

$$
d_{2}=\left(h-d_{1}\right) \frac{\sigma_{z}^{\prime}}{E_{b}},
$$

where $E_{b}$ is the Young's modulus of the filling body, GPa, and $\sigma_{z}^{\prime}$ is the overlying strata load borne by the filling body during the second-stage mining, MPa.
4.2.3. Immediate Roof Settlement $d_{3}$. When the coal pillar is replaced by the filling body, the load of the overlying strata in the coal is borne by all filling bodies. According to the elastic foundation assumption [25], the subsidence of any point on the foundation surface is proportional to the pressure on that point, which can be determined as

$$
2 b \gamma^{\prime} H^{\prime}=\frac{E_{b} b}{h-d_{1}}\left(d_{2}+d_{3}\right)+\frac{E_{b} b}{h-d_{1}-d_{2}} d_{3},
$$




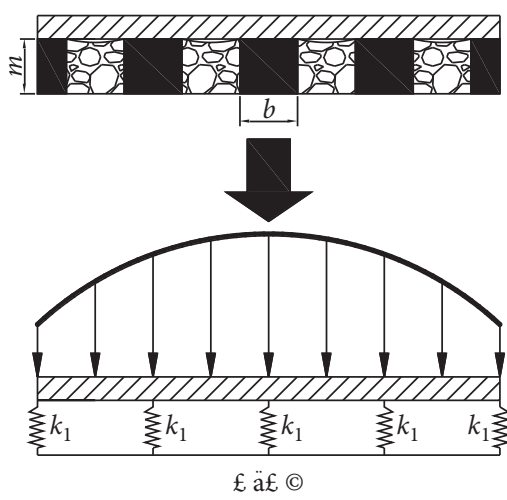

(a)

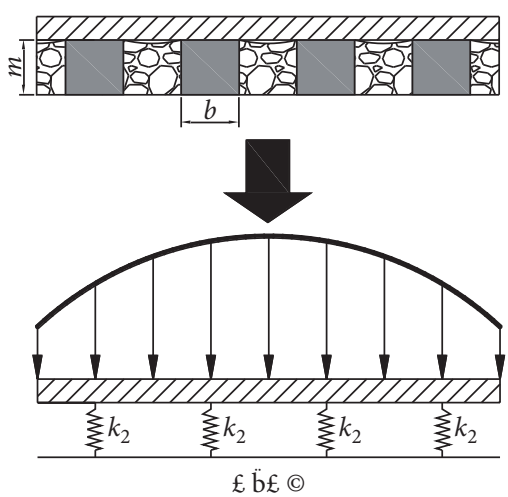

(b)

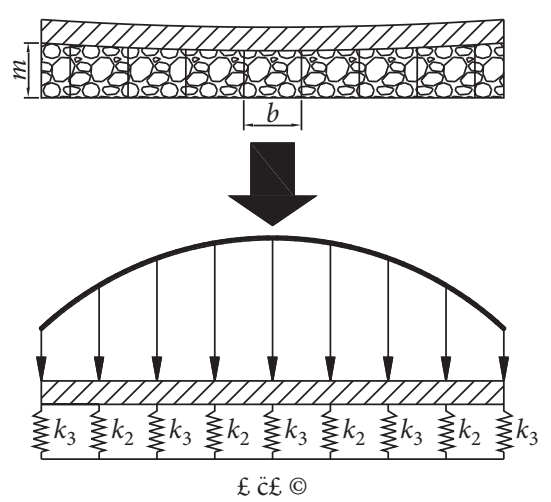

(c)

Figure 6: Mechanics model of RBM. (a) First stage. (b) Second stage. (c) Third stage.

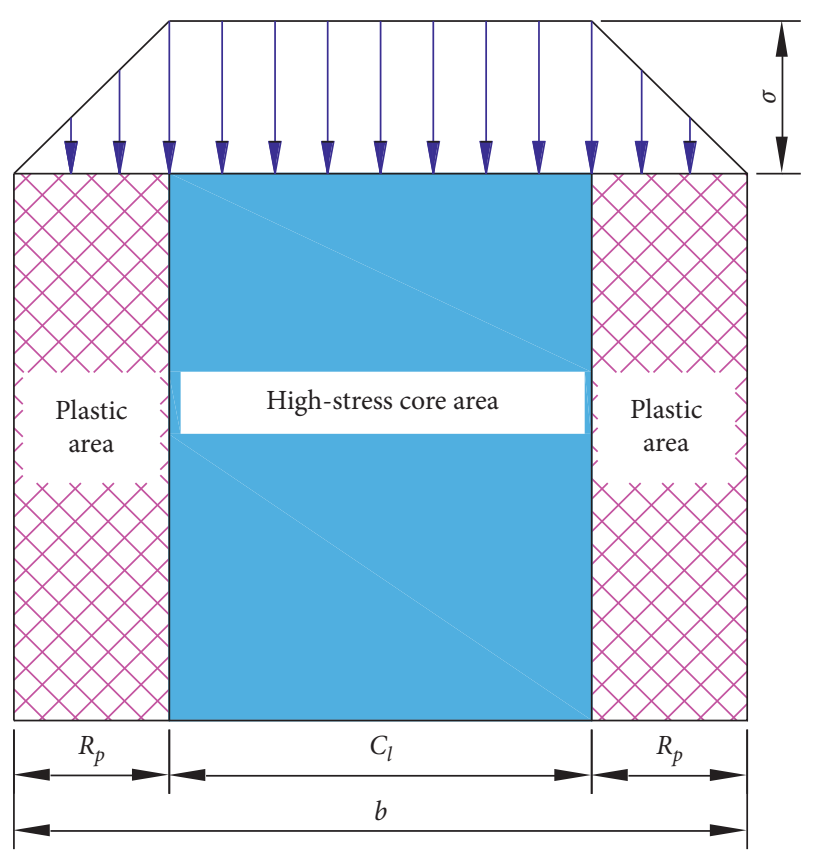

Figure 7: Distribution pattern of the load borne by the coal pillar.

where $\gamma^{\prime}$ is the average bulk density of the overlying strata, $\mathrm{kN} \cdot \mathrm{m}^{-3}, H^{\prime}$ is the buried depth of the coal seam, m, and $d_{3}$ can be determined according to the following formula:

$$
d_{3}=\frac{2 \gamma^{\prime} H^{\prime}\left(h-d_{1}\right)-E_{b} d_{2}}{\left(2 h-2 d_{1}-d_{2}\right) E_{b}}\left(h-d_{1}-d_{2}\right) .
$$

Then, the maximum settlement of the immediate roof is

$$
d=d_{1}+\left(h-d_{1}\right) \frac{\sigma_{z}^{\prime}}{E_{b}}+\frac{2 \gamma^{\prime} H^{\prime}\left(h-d_{1}\right)-E_{b} d_{2}}{\left(2 h-2 d_{1}-d_{2}\right) E_{b}}\left(h-d_{1}-d_{2}\right) .
$$

According to the conditions of the Chahasu Mine, the elastic modulus $E_{c}$ of the coal seam is $2.0 \mathrm{GPa}$, Poisson's ratio $\mu_{c}$ is 0.24 , internal friction angle $\varphi$ is $28^{\circ}$, cohesive force $c$ is $2 \mathrm{MPa}$, elastic modulus $E_{b}$ of the filling body is $0.82 \mathrm{GPa}$, Poisson's ratio $\mu_{b}$ is 0.25 , and immediate roof settlement is $117.5 \mathrm{~mm}$.
According to the experimental mechanical parameter test of on-site coal samples and filling bodies, the elastic modulus $E_{c}$ of the coal seam is $2.0 \mathrm{GPa}$, Poisson's ratio $\mu_{c}$ is 0.24 , internal friction angle $\varphi$ is $28^{\circ}$, cohesive force $c$ is $2 \mathrm{MPa}$, elastic modulus $E_{b}$ of the filling body is $0.82 \mathrm{GPa}$, and Poisson's ratio $\mu_{b}$ is 0.25 , and it can be calculated that the immediate roof settlement is $117.5 \mathrm{~mm}$.

\section{Numerical Simulation}

5.1. Numerical Model. In order to study the stability of the coal pillar and the roof stress and deformation evolution law of the RBM, taking the engineering geological conditions of Chahasu Mine as the background, a numerical model is established using the FLAC3D, as shown in Figure 8. The size of the model is $240 \mathrm{~m} \times 1 \mathrm{~m} \times 150 \mathrm{~m}$. The constitutive relationship is the Mohr-Coulomb criterion. In order to eliminate boundary effects, $80 \mathrm{~m}$ coal pillars are reserved on both sides of the model, and the horizontal displacement around the model and the vertical displacement at the bottom are fixed; the mechanical parameters are shown in Table 1.

After the model is established, the initial balance calculation is carried out. In the first phase, a $5 \mathrm{~m}$ coal pillar was excavated, leaving $15 \mathrm{~m}$ and backfilled; in the second phase, the middle $5 \mathrm{~m}$ of the $15 \mathrm{~m}$ coal pillar was excavated and backfilled; the subsequent phases 3 and 4 were excavated and backfilled with $5 \mathrm{~m}$ coal pillars on the left and right sides, respectively, and a total of 20 branches were excavated. During the mining and backfilling process, the deformation and stress state of the stope roof are monitored.

\subsection{Result Analysis}

5.2.1. Analysis of Stress. As shown in Figure 9, during the entire mining process, the coal pillars and filling bodies are alternately loaded, and the vertical stress above the working face is distributed in a pressure arch shape with the mining of the working face. As mining continues to advance, the pressure arches continue to merge, rise, and expand, and the compressive stress of the stope continuously shifts from the side of the working face to the coal wall. 

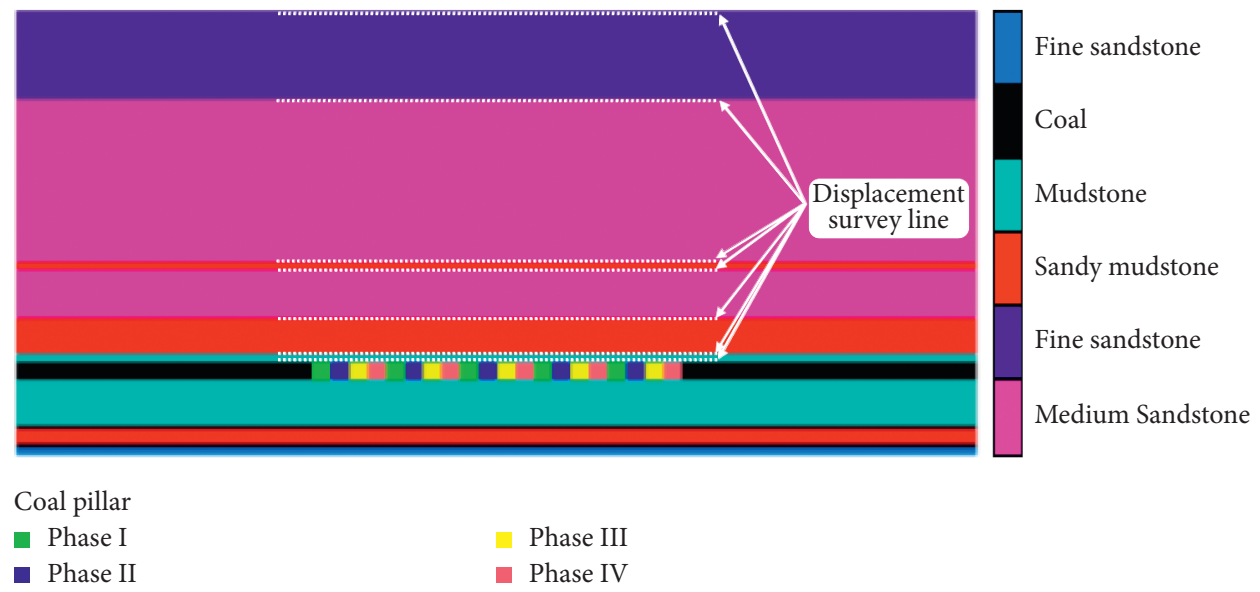

FIgURE 8: RBM calculation model.

TABle 1: Physical and mechanical parameters of each rock formation.

\begin{tabular}{lcccccc}
\hline Lithology & $\begin{array}{c}\text { Density } \\
\left(\mathrm{kg} \cdot \mathrm{cm}^{3}\right)\end{array}$ & $\begin{array}{c}\text { Tensile strength } \\
(\mathrm{MPa})\end{array}$ & $\begin{array}{c}\text { Cohesion } \\
(\mathrm{MPa})\end{array}$ & $\begin{array}{c}\text { Internal friction } \\
\text { angle }\left(^{\circ}\right)\end{array}$ & $\begin{array}{c}\text { Bulk modulus } \\
(\mathrm{GPa})\end{array}$ & $\begin{array}{c}\text { Shear modulus } \\
(\mathrm{GPa})\end{array}$ \\
\hline Fine sandstone & 2550 & 2.5 & 1.13 & 30 & 6.20 & 4.15 \\
Medium sandstone & 2500 & 2.4 & 1.12 & 30 & 6.17 & 6 \\
Mudstone & 2100 & 0.5 & 0.22 & 29 & 28 & 5 \\
Coal & 1400 & 1.2 & 2.0 & 28 & 0.94 & 0.63 \\
Sandy mudstone & 2200 & 0.6 & 1 & 29 & 0.9 & 1.4 \\
Filling body & 1100 & 1.2 & 1.3 & & & 0.5 \\
\hline
\end{tabular}

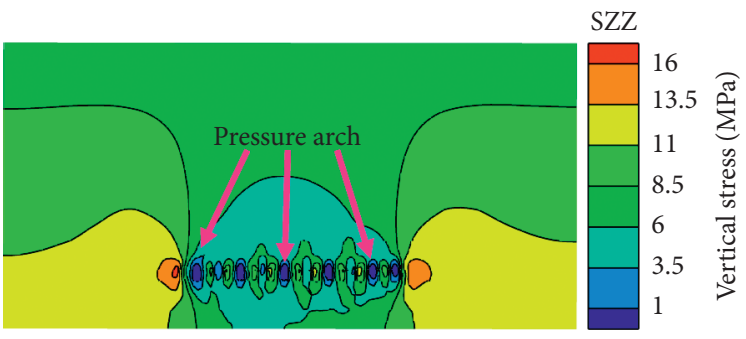

(a)

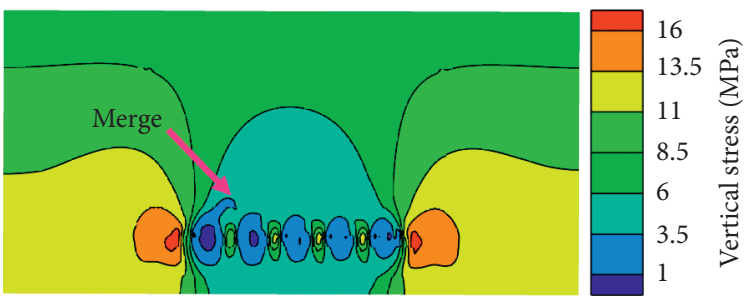

(b)

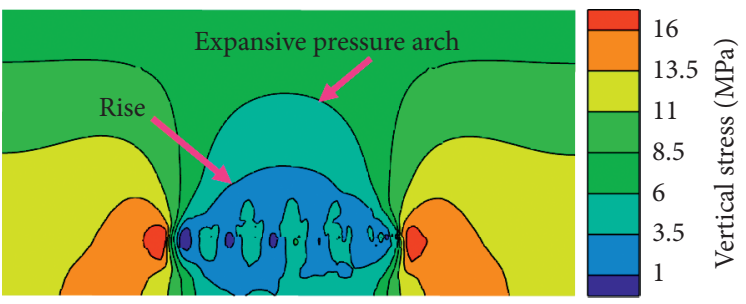

(c)

Figure 9: Vertical stress. (a) First stage. (b) Second stage. (c) Third stage.

After the first stage mining, the coal pillar is the main bearing body. After the first phases of mining and backfilling, the vertical stress in the central stress core area of the coal pillar is rised to $16 \mathrm{MPa}$, and the roof above the branch formed a pressure arch distribution. The filling body is not completely compacted, and the compressive stress is $1 \sim 3 \mathrm{MPa}$ at this stage; after the second-stage mining, the first-stage filling body is fully in contact with the roof and becomes the main bearing body, and the compressive stress is $7-9 \mathrm{MPa}$, and the pressure arch above the roof of the branch started to merge and rise, and the second-stage filling body compressive stress is $1 \sim 3 \mathrm{MPa}$; when the second-stage filling body is connected to the roof, the load of the overlying strata is borne by all filling bodies, and finally, a supporting 
system dominated by filling bodies is formed to bear the weight of the overlying strata.

5.2.2. Analysis of Roof Subsidence. As shown in Figure 10, the amount of overlying strata subsidence on the working face gradually increases with the staged mining. The immediate roof and main-roof subsidence curves are $w$-shaped with repeatedly upward and downward fluctuations. The rock above the main roof mainly sinks slowly, which can maintain integrity and continuity, and the closer it is to the center of the working face, the greater the amount of the sinking.

After the first stage of mining, the roof is mainly supported by coal pillars. The maximum settlement of the roof above the branch is $114 \mathrm{~mm}$, and the maximum settlement of the main roof is $63.4 \mathrm{~mm}$; in the second stage of the mining, the remaining coal pillars are replaced by the filling bodies, and the first-stage filling body is gradually compacted. At this time, the maximum settlement of the immediate roof is $150.5 \mathrm{~mm}$, and the maximum settlement of the main roof is $136 \mathrm{~mm}$; when the second-stage filling body is connected to the roof, all the filling bodies bear the load of the overlying strata together. The subsidence of the roof continues to increase, and the maximum settlement of the immediate roof is $160 \mathrm{~mm}$. Due to the different degree of compaction and stability, the curve still fluctuates. During the entire mining process, the roof gradually sinks, and the subsidence of the roof is apparently lower than that of caving mining, indicating that the RBM can effectively limit the subsidence and deformation of the overlying strata.

It can be seen from the above results that the numerical results are similar to the theoretical calculation results in Section 4. By adopting the RBM method, the coal pillars and filling bodies can maintain good stability, and the roof subsidence can be controlled within a reasonable range.

\section{Engineering Practice}

6.1. Main Parameters of the Working Face. The engineering practice site is located at the 301 working face of the 31st mining area in Chahasu Coal Mine, with a branch width of $5 \mathrm{~m}$ and a length of $50 \mathrm{~m}$; the filling materials are composed of the coal gangue, cement, fly ash, and mine water, with the weight ratio of $980: 260: 350: 400$; the particle size of the gangue after crushing is no more than $15 \mathrm{~mm}$. After 28 days, the strength of the filling body can reach about $9 \mathrm{MPa}$. Figure 11 shows the actual effect of the roadways after backfilling. Up to now, the 301 face has been fully recovered.

6.2. Application Effect. In order to evaluate the effect of $\mathrm{RBM}$, during the mining process, the borehole stress gauge is arranged in the coal pillar and filling body to monitor the stress variation characteristics, and the roof subsidence of the branch is monitored, and the TS-C0601 drilling imaging analyzer is used to monitor the roof of the branch, and the monitoring information mainly includes coal pillar supporting pressure, filling body pressure, roof subsidence, and roof crack development status. Figure 12 shows the sketch diagram of the main monitoring equipment. Figure 13 shows the results of the filling body, coal pillar stress monitoring, and roof subsidence monitoring, respectively. Figure 14 shows the drilling observation results of the filling body, coal pillar, and roof.

From the monitoring data, it can be seen that, in the first stage of the mining process, the coal pillar is the main bearing body; the maximum supporting pressure is $16.5 \mathrm{MPa}$, and the filling body is not completely compacted; the force changes slowly, and the maximum value is $2.3 \mathrm{MPa}$. The maximum settlement of the roof is $38 \mathrm{~mm}$; during the second stage of the mining process, the maximum supporting pressure of the coal pillar was $11.5 \mathrm{MPa}$, and the filling body gradually became the main bearing body, the pressure value increased to $7.1 \mathrm{MPa}$, and the maximum settlement of the roof was $102 \mathrm{~mm}$. Drilling peeping observation results showed that there are a small number of vertical cracks within $1 \mathrm{~m}$ away from the surface of the coal pillar and the filling body, and the deep coal body and the filling body are relatively complete within $1 \mathrm{~m}$, and in the partial separation layers, the vertical cracks are within $2 \mathrm{~m}$ away from the surface of the roof. The above roof is relatively complete, and the cracks only developed to the immediate roof.

As shown in Figure 15, during the entire mining process, the filling body was well connected to the roof, and the coal pillars were able to maintain stability, and there was no obvious slabbed spalling phenomenon. A total of about 145,000 tons of coal was mined, and processing gangue was about 260,000 tons, and fly ash was about 90,000 tons. Through adopting RBM technology, both coal pillars and filling bodies can maintain good stability and efficiently constrict the deformation of the stope roof and overlying strata.

\section{Discussion}

Compared with the longwall backfill mining, the RBM working face layout and mining method are more flexible. The coal mining and filling are carried out in different branches without interfering with each other. The roof is exposed at one time, and the ground deformation is reduced, indicating that the RBM has great potential.

In the process of staged mining, the width of the general branch is between 4.5 and $6 \mathrm{~m}$. If the coal pillar yields and fails under the load of the overlying strata, the pressure of the overlying strata will be borne by the adjacent coal pillars, thus forming an expansive pressure arch. If the width of the coal pillar is wide enough, then a part of the original rock stress area could exist in the middle of the coal pillar. In this case, the number of branches is not limited.

In RBM, coal pillar size, filling rate, filling body strength, and time effect of the filling body will affect the roof control effect. Further consideration should be given to the support strength of the coal pillar, the lateral effect of the filling body on the coal pillar, and the time effect on the strength of coal pillars. Through theoretical analysis, numerical simulation, and on-site test, it is simulated that the roof settlement in the mining area is $117.5 \mathrm{~mm}, 160 \mathrm{~mm}$, and $102 \mathrm{~mm}$. The results 

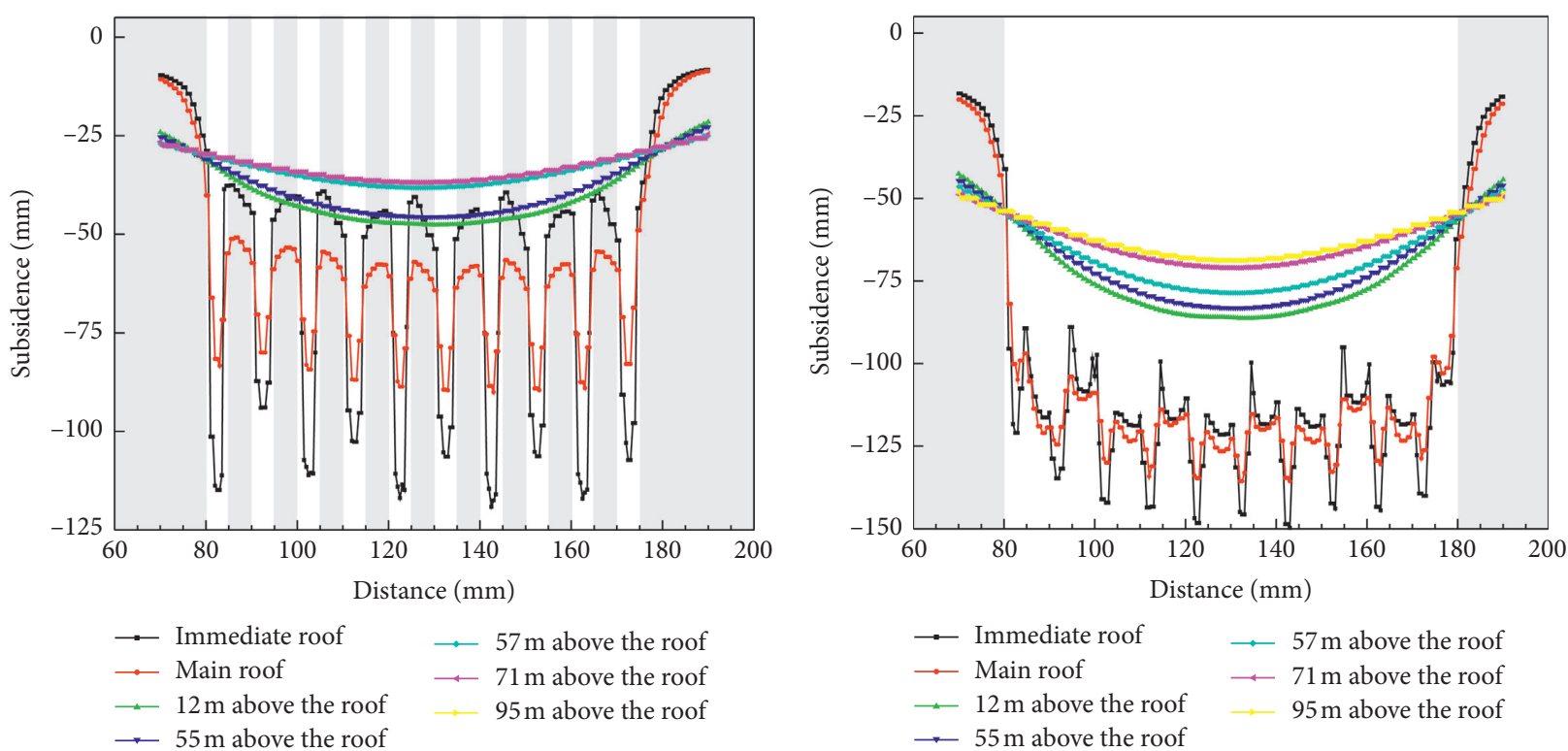

(a)

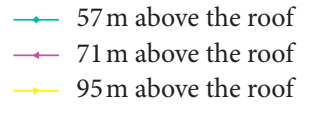

(b)

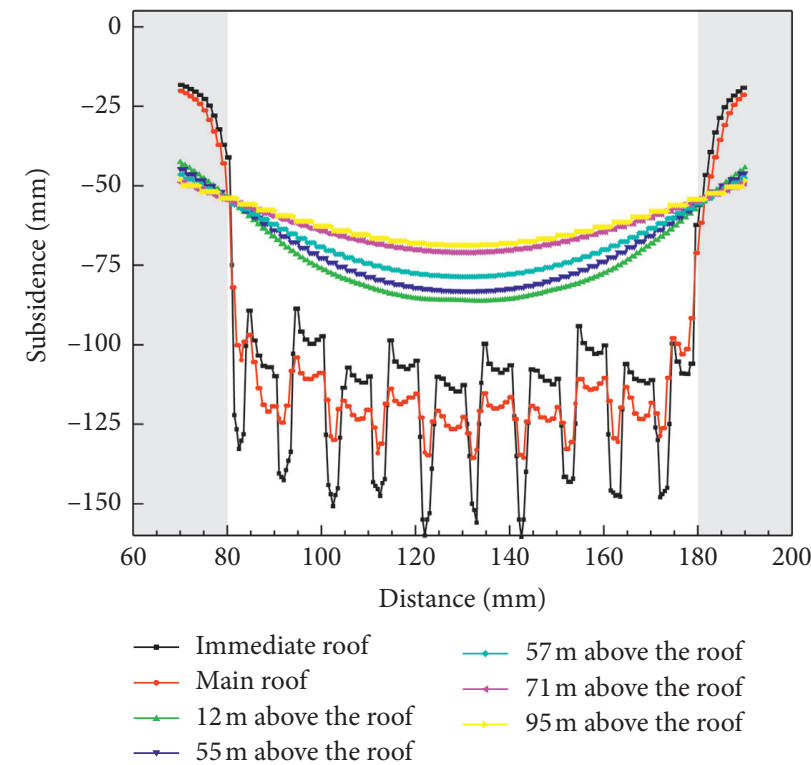

(c)

Figure 10: Roof sinking curve. (a) First stage. (b) Second stage. (c) Third stage.
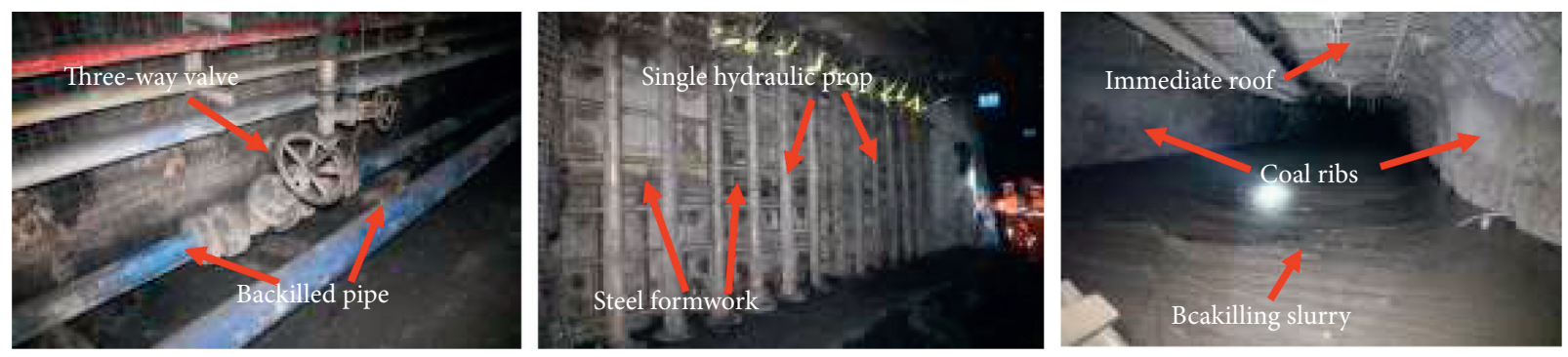

Figure 11: Photo of the backfilling effect. 


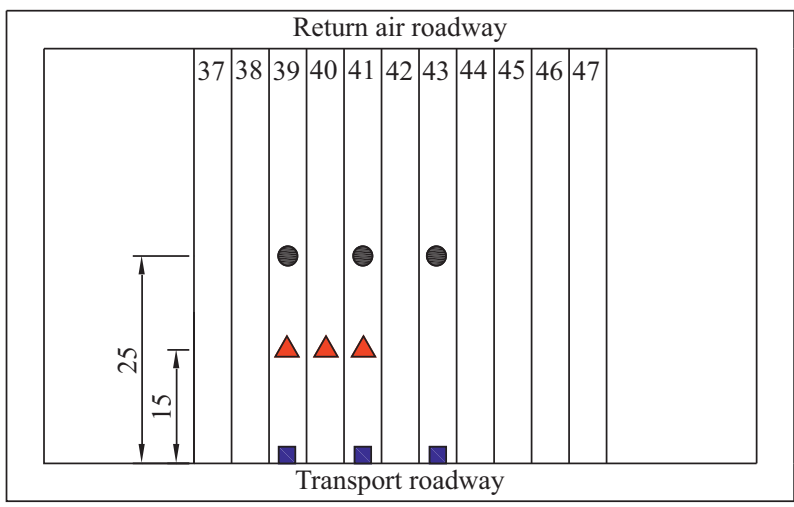

Filling body stress

Coal pillar stress

- Roof subsidence

FIGURE 12: Schematic diagram of the measuring point layout.

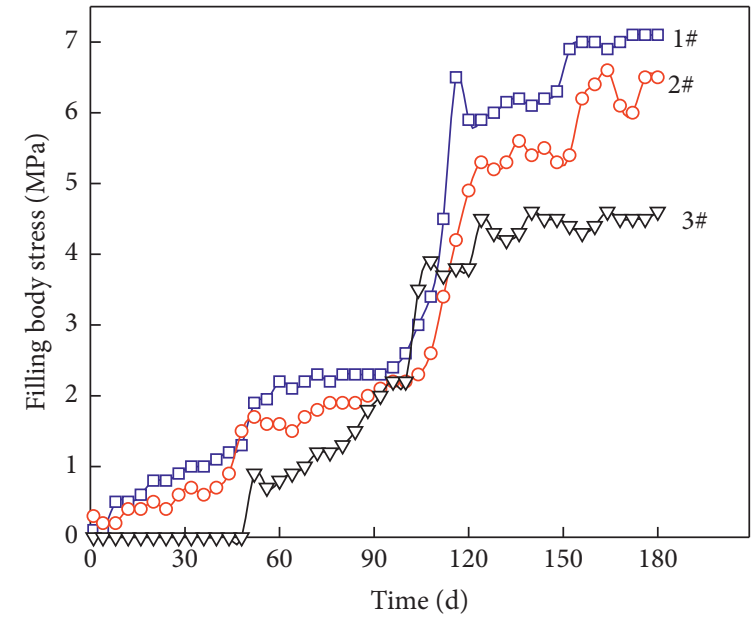

(a)

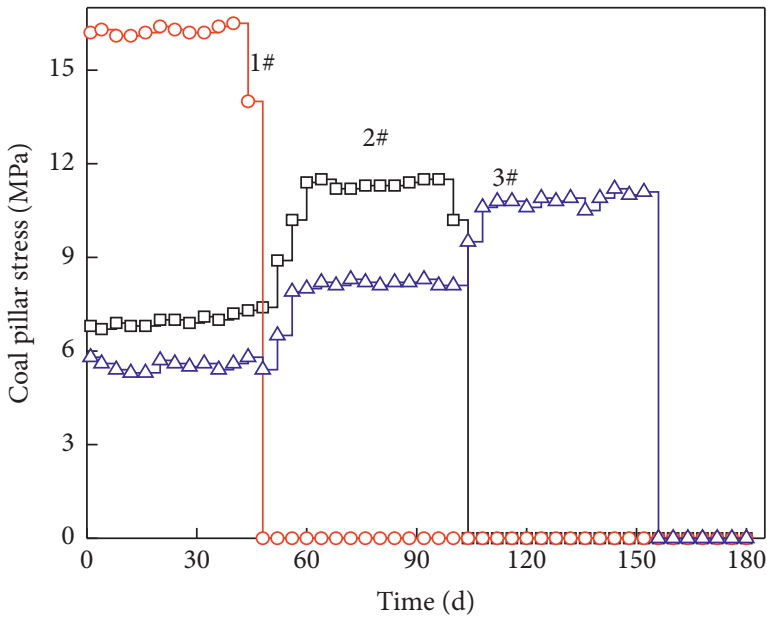

(b)

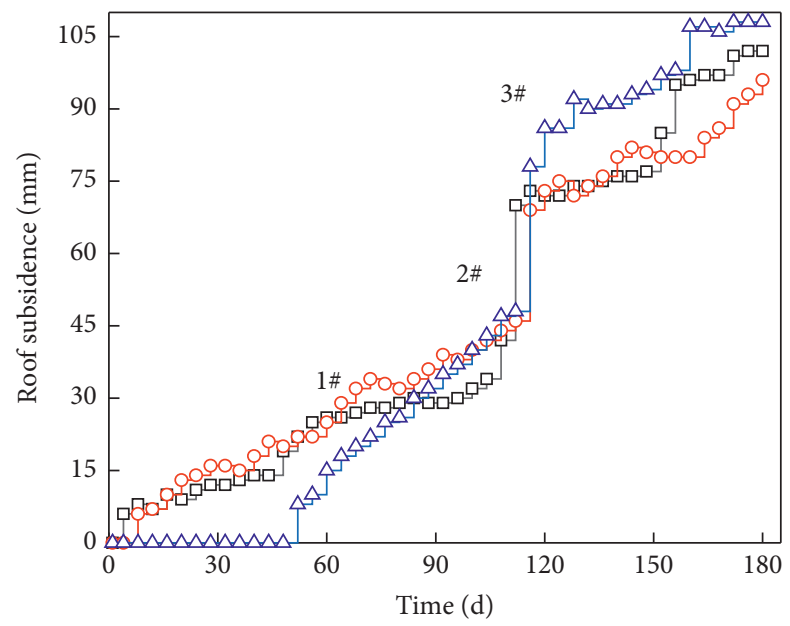

(c)

FIGURe 13: Monitoring data. (a) Backfilling body stress. (b) Coal pillar stress. (c) The amount of roof subsidence.

on the site are the smallest, which may be due to the repeated filling of the uncovered area with slurry, thereby increasing the filling rate.
If the RBM technology is adopted in the mining area to deal with coal gangue and the requirements for surface subsidence are not strict, then in the second-stage filling, the 

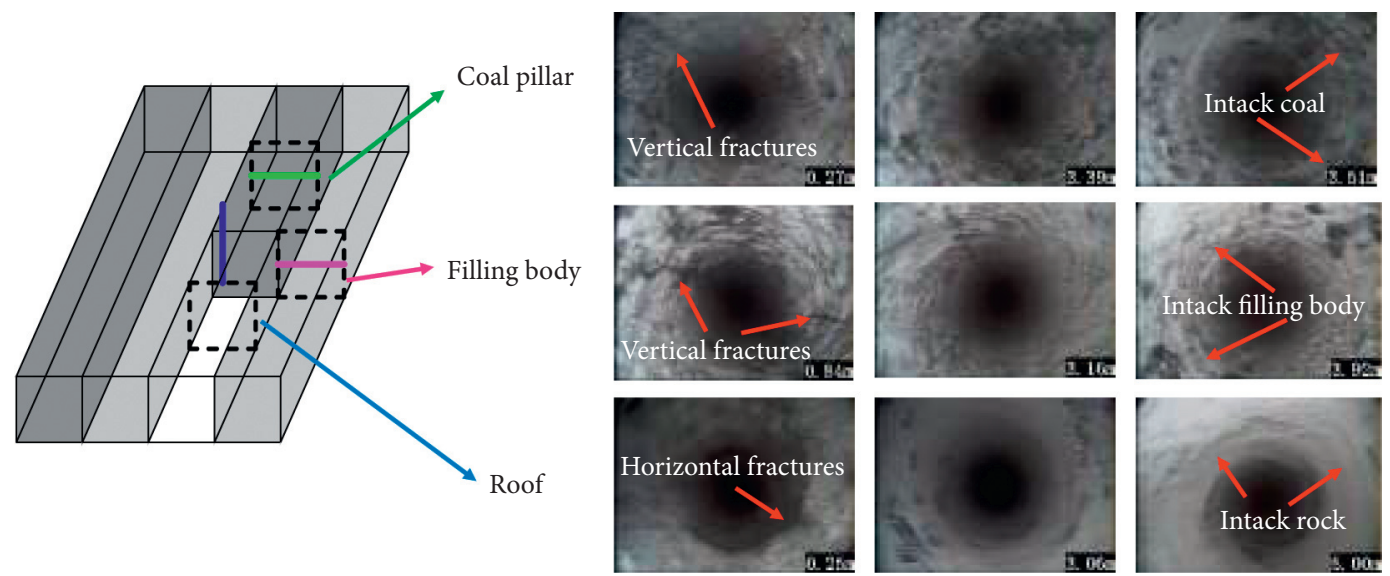

FIgURE 14: Borehole image.

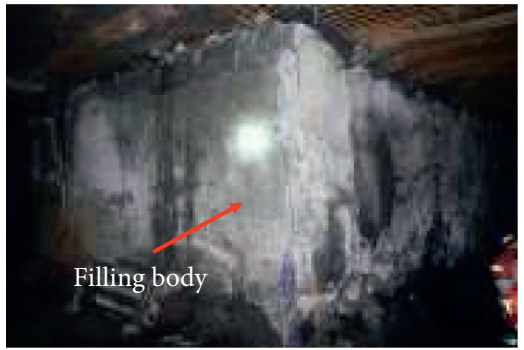

(a)

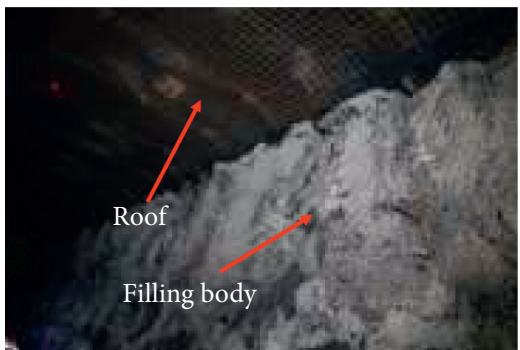

(b)

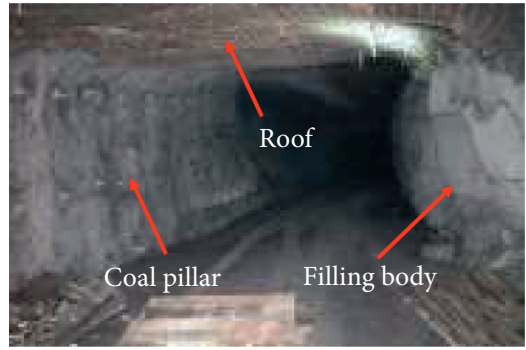

(c)

FIgURE 15: Backfilling body. (a) The exposed filling body. (b) The top of the filling body. (c) Coal pillar.

amount of cement can be reduced, the strength of the filling body can be reduced, or the coal gangue can be directly filled to reduce the filling cost.

\section{Conclusion}

This paper takes the 301 backfill mining test face in Chahasu Coal Mine as the background and explores the influence of the stability of the coal pillar group in $\mathrm{RBM}$ on the movement of the stope roof, and the following conclusions are obtained:

(1) Based on the theory of expansive pressure arch, the stability mechanics model of the coal pillar group for RBM is established. When the height and width of the branch are both $5 \mathrm{~m}$, the number of branches does not exceed 52 in one cycle to ensure the stability of the coal pillar.

(2) The pressure arch evolution of the RBM is divided into three stages: the formation of local pressure arches, the merging of pressure arches, and the expansion of pressure arch uplift. The immediate roof subsidence mechanics model is established, and the maximum immediate roof settlement is calculated in stages to $117.5 \mathrm{~mm}$.

(3) Numerical results showed that coal pillars and filling bodies are alternately loaded during the mining process. The peak supporting pressure of coal pillars is $16 \mathrm{MPa}$, and the maximum pressure of filling bodies is $9 \mathrm{MPa}$; the sinkage of both the immediate roof and the main roof showed a $w$-shape. The maximum settlement of the immediate roof is $160 \mathrm{~mm}$, and the overlying strata above the main roof sinks slowly.

(4) Engineering practice showed that the coal pillar is stable in the process of mining. The maximum supporting pressure of the coal pillar is $16.5 \mathrm{MPa}$, and the maximum pressure of the filling body is 7.1 $\mathrm{MPa}$. The immediate roof of the working face sinks in stages, and the maximum settlement is $102 \mathrm{~mm}$. The filling body has a good control effect on the roof, achieving the purpose of controlling the movement of the overlying strata and processing industrial waste.

\section{Data Availability}

The data used to support the findings of this study are included within this article.

\section{Conflicts of Interest}

The authors declare that there are no conflicts of interest. 


\section{Acknowledgments}

The authors sincerely appreciate the financial support from the National Natural Science Foundation of China (no. 51804310). The help of the Chahasu Mine is gratefully acknowledged.

\section{References}

[1] M. G. Qian, X. X. Miao, and J. L. Xu, "Green mining of coal resources harmonizing with environment," Journal of China Coal Society, vol. 32, no. 1, pp. 1-7, 2007.

[2] L. M. Fan, X. D. Ma, Y. H. Li et al., "Geological disasters and control technology in high intensity mining area of western China," Journal of China Coal Society, vol. 42, no. 2, pp. 276-285, 2017.

[3] Research Group of National Key Basic Research Program of China (2013CB227900) (Basic Study on Geological Hazard Prevention and Environmental Protection in High Intensity Mining of Western Coal Area), "Theory and method research of geological disaster prevention on high-intensity coal exploitation in the west areas," Journal of China Coal Society, vol. 42 , no. 2, pp. 267-275, 2017.

[4] X. K. Sun and X. H. Li, "The new technology of waste-filling replacement mining on strip coal pillar," Journal of China Coal Society, vol. 3, pp. 259-263, 2008.

[5] G. R. Feng, X. Q. Jia, Y. X. Guo et al., "Study on mixture ratio of gangue-waste concrete cemented paste backfill," Journal of Mining \& Safety Engineering, vol. 33, no. 6, pp. 1072-1079, 2016.

[6] M. G. Qian, X. X. Miao, and J. L. Xu, "Coal mine green mining technology," Journal of China University of Mining \&Technology, vol. 4, pp. 5-10, 2003.

[7] F. T. Wang, S. H. Tu, Z. X. Li, H. S. Tu, and F. Chen, "Mutation instability mechanism of the room mining residual pillars in the shallow depth seam," Journal of Mining \& Safety Engineering, vol. 29, no. 6, pp. 770-775, 2012.

[8] B. An, X. Miao, J. Zhang, F. Ju, and N. Zhou, "Overlying strata movement of recovering standing pillars with solid backfilling by physical simulation," International Journal of Mining Science and Technology, vol. 26, no. 2, pp. 301-307, 2016.

[9] B. N. Hu, W. H. Zhang, Q. C. Gao, and P. L. Liu, "Test research on permanent pillar mining with coal refuse backfilling," Coal Science and Technology, vol. 11, pp. 46-48, 2006.

[10] B. Q. Wang, S. C. Gu, Q. Fan, and X. B. Li, "Design method of mining room coal pillar in stripe filling mining," Coal Engineering, vol. 49, no. 6, pp. 1-5, 2017.

[11] B. Lu, X. G. Zhang, F. Li, B. L. Zhang, and Z. Z. Pang, "Study and application of short-wall gangue cemented backfilling technology," Journal of China Coal Society, vol. 42, no. S1, pp. 7-15, 2017.

[12] H. Wang, B. A. Poulsen, B. Shen, S. Xue, and Y. Jiang, "The influence of roadway backfill on the coal pillar strength by numerical investigation," International Journal of Rock Mechanics and Mining Sciences, vol. 48, no. 3, pp. 443-450, 2011.

[13] B. F. An, D. D. Wang, J. L. Pang, H. Zhang, and G. L. Cao, "Physical simulation for surrounding rock deformation and bearing capacity of pillars in working face with backfilling mining to recover room mining standing pillars," Rock and Soil Mechanics, vol. 46, no. 12, pp. 1-9, 2020.

[14] W. Yu, B. Pan, F. Zhang, S. Yao, and F. Liu, "Deformation characteristics and determination of optimum supporting time of alteration rock mass in deep mine," KSCE Journal of Civil Engineering, vol. 23, no. 11, pp. 4921-4932, 2019.
[15] W. J. Yu, G. S. Wu, B. F. An, and P. Wang, "Experimental study on the brittle-ductile response of a heterogeneous soft coal rock mass under multifactor coupling," Geofluids, vol. 2019, Article ID 5316149, 15 pages, 2019.

[16] W. J. Yu and K. Li, "Deformation mechanism and control technology of surrounding rock in the deep-buried large-span chamber," Geofluids, vol. 2020, Article ID 8881319, 22 pages, 2020.

[17] Y. Zhang, S. G. Cao, X. P. Lai, C. Z. Zhao, and S. Y. Du, "Study on the development mechanism and control of water-conducting fractures in short-wall block backfill mining," Journal of Mining \& Safety Engineering, vol. 36, no. 6, pp. 1086-1092, 2019.

[18] Q. Sun, J. X. Zhang, W. Yin, N. Zhou, and L. Yang, "Study of stability of surrounding rock and characteristic of overburden strata movement with longwall roadway backfill coal mining," Journal of China Coal Society, vol. 42, no. 2, pp. 404-412, 2017.

[19] X. J. Deng, J. X. Zhang, P. Huang, Q. Zhang, and X. F. Hao, "Roof movement characteristics in extra thick coal seam mining with the upward slicing filling technology," Journal of China Coal Society, vol. 40, no. 5, pp. 994-1000, 2015.

[20] L. Y. Qin, C. W. Liu, and Y. Q. Fang, "Research on expansive pressure arch theory and rock pillar load about the activity of the covered rock mass in close distance," Metal Mine, vol. 12, pp. 20-24, 2007.

[21] J. X. Zhang, X. X. Miao, X. B. Mao, and Z. W. Chen, "Research on waste substitution extraction of strip extraction coal-pillar mining," Chinese Journal of Rock Mechanics and Engineering, vol. 26, no. S1, pp. 2687-2693, 2007.

[22] S. J. Chen, J. W. Zhang, D. W. Ying et al., "Mechanism and numerical simulation of filling walls improving performance of coal pillar," Journal of Mining \& Safety Engineering, vol. 34, no. 2, pp. 268-275, 2017.

[23] W. J. Yu and W. J. Wang, "Strate movement induced by coalpillar under three circumstances exchanged by gangue backfill and quadratic stability law," Chinese Journal of Rock Mechanics and Engineering, vol. 30, no. 1, pp. 105-112, 2011.

[24] A. H. Wilson and J. L. Sun, "Research on determining the size of coal pillar," Mine Surveying, vol. 1, pp. 30-42, 1973.

[25] L. X. Wu and J. Z. Wang, "Calculation of yield zone width of coal pillar and analysis of its influencing factors," Journal of China Coal Society, vol. 6, pp. 625-631, 1995.

[26] X. X. Miao, F. Ju, Y. L. Huang, and G. L. Guo, "New development and prospect of backfilling mining theory and technology," Journal of China University of Mining \&Technology, vol. 44, no. 3, pp. 391-399, 2015. 